\title{
Comparison of safety and toxicity of liposomal doxorubicin vs. conventional anthracyclines: a meta-analysis
}

Shamudheen M Rafiyath', Mohammad Rasul', Byung Lee ${ }^{1}$, Guoging Wei ${ }^{2}$, Gurpreet Lamba ${ }^{1}$ and Delong Liu ${ }^{* *}$

\begin{abstract}
Background: Liposomal formulations of anthracyclines appear to have favorable toxicity profile when compared with conventional anthracyclines in elderly, high risk cardiac patients and patients with prior use of anthracyclines. Randomized controlled trials have evaluated the efficacy and safety profile of liposomal formulations with conventional anthracyclines. Our aim is to evaluate the adverse effects and quantify the relative safety profile of the liposomal and conventional anthracyclines through meta-analysis of the published randomized trials.

Methods: We conducted a broad search strategy of major electronic databases. We performed a meta- analysis of adverse effects on randomized controlled trials comparing liposomal formulation and conventional anthracyclines on different tumors. The primary outcome was the adverse effects including congestive heart failure (CHF), hematological toxicity, palmar-plantar erythrodysthesias (PPE), alopecia, nausea and vomiting. The odds ratios of the adverse effects were calculated separately and the overall odds ratio of the pooled data was calculated.

Results: We identified nine randomized controlled trials comparing liposomal formulations and conventional anthracyclines. The study included 2220 patients, of which1112 patients were treated with liposomal formulations and 1108 were treated with conventional anthracyclines. We found that the liposomal formulations have low incidence of $\mathrm{CHF}(\mathrm{OR} 0.34,95 \% \mathrm{Cl}, 0.24-0.47)$, alopecia (OR 0.0.25, 95\% Cl, 0.0.10-0.62), neutropenia (OR 0.62, 95\% Cl, $0.45-0.85),(\mathrm{OR} 0.89,95 \% \mathrm{Cl}, 0.71-1.125)$, and thrombocytopenia (OR $0.87,95 \% \mathrm{Cl}, 0.61-1.25)$. The incidence of PPE was similar in both arms (OR 1.08, 95\% Cl, 0.11- 10.30).

Conclusions: Liposomal doxorubicin and pegylated liposomal doxorubicin demonstrated favorable toxicity profiles with better cardiac safety and less myelosuppression, alopecia, nausea and vomiting compared with the conventional anthracyclines. The better therapeutic index of liposomal anthracyclines without compromising the efficacy makes it a favorable choice over conventional anthracyclines in elderly patients, patients with risk factors for cardiac disease and patients with prior use of anthracyclines.
\end{abstract}

\section{Introduction}

Anthracyclines have become one of the most important drugs for the treatment of both hematological and solid tumors [1-3]. Conventional anthracyclines have a relatively low therapeutic index [4]. The risk of cardiotoxicity increases with higher cumulative doses of anthracyclines [4-7]. It is recommended that the cumulative life time dose of doxorubicin should not exceed

\footnotetext{
* Correspondence: delong_liu@nymc.edu.

'Division of Hematology and Oncology, New York Medical College and Westchester Medical Center, Valhalla, NY 10595, USA

Full list of author information is available at the end of the article
}

$450-500 \mathrm{mg} / \mathrm{m} 2$. Anthracycline cardiotoxicity is an issue not only when it is administered as a single agent, but also when it is combined with other agents such as trastuzumab, which is a cardio toxic agent by itself [8]. The mechanisms for cardiotoxicity are mainly due to the development of cardiomyopathy as the result of free radical damage to the myocytes. The toxicity increases with high peak plasma anthracycline levels [9]. Repeated damage to the mitochondria of myocytes by the free radicals is believed to contribute to cumulative cardiomyopathy [10]. Several liposomal formulations of anthracyclines have been developed to increase the therapeutic index of anthracyclines.

\section{Biomed Central}


The liposome-encapsulated anthracyclines was designed to reduce the toxicity of doxorubicin while preserving its antitumor efficacy by altering its tissue distribution and pharmacokinetics. Intravenously injected liposomes cannot escape the vascular space in sites that have tight capillary junctions, such as the heart muscle and gastrointestinal tract. The liposomes generally exit the circulation in tissues and organs lined with cells that are not tightly joined (fenestrated) or areas where capillaries are disrupted by inflammation or tumor growth. Thus, liposomes should preferentially direct doxorubicin away from sites of potential toxicity, but leave the tumor exposed [11]. Liposomal doxorubicin was associated with significantly less cardiac and gastrointestinal toxicity, while antitumor efficacy was at least comparable to that of the parent molecule $[12,13]$.

Doxil/Caelyx is a Pegylated (polyethylene glycol coated) liposome-encapsulated (PLD) form of doxorubicin $[4,7,14]$. Doxil has preferential concentration in the skin because of the polyethylene glycol coating. The main dose limiting side effects associated with Doxil is the palmar plantar erythrodysesthesia (PPE), otherwise known as hand-foot syndrome. Following administration of Doxil, small amounts of the drug can leak from capillaries in the palms of the hands and soles of the feet. The result of this leakage is redness, tenderness, and peeling of the skin that can be uncomfortable and even painful. The prevalence of this side effect limits the Doxil dose that can be given as compared with doxorubicin in the same treatment regimen. Outside the United States, Doxil is known as Caelyx.

Myocet is a non-pegylated liposomal doxorubicin which is approved in Europe and Canada for treatment of metastatic breast cancer in combination with cyclophosphamide. The rationale behind its design is similar to Doxil [15-20]. Unlike Doxil, the myocet liposome does not have a polyethylene glycol coating and therefore does not result in the same prevalence of Hand-Foot Syndrome. The minimization of this side effect may allow 1: 1 substitution with doxorubicin in the same treatment regimen, thereby improving safety with no loss of efficacy.

DaunoXome ${ }^{\circledR}$ is a non-pegylated liposomal daunorubicin which is indicated in U.S for the first line treatment of Advanced AIDS-related Kaposi's sarcoma [4].

Randomized trials comparing liposomal anthracyclines with conventional anthracyclines invariably present similar or higher efficacy with the liposomal anthracyclines. We performed a meta-analysis from nine randomized controlled trials of various tumors comparing the outcome and the adverse effects of conventional anthracyclines and liposome encapsulated or pegylated liposomal anthracyclines. To our knowledge this is the first metaanalysis comparing the safety of the conventional anthracyclines and the liposome encapsulated anthracyclines.

\section{Methods}

We used a broad search strategy with special emphasis on randomized controlled trials. We used a variety of electronic databases, including MEDLINE via Pub MED, Ovid, and the Cochrane library.

First we identified key terms of the study drugs "liposomal doxorubicin", "Doxil" "Myocet", "Doxorubicin", "Daunorubicin", "Epirubicin","Mitoxantrone", and "Idarubicin". The key word "liposomal doxorubicin" compared with "Doxorubicin" was searched using the MeSH subheadings without any language barrier. The searches were combined with the key word search "randomized controlled trials". 480 related articles were found, but only randomized controlled trials comparing liposomal doxorubicin and conventional anthracycline were selected for the meta-analysis. The selected randomized articles were again searched for related topics on the Pub MED database. We also searched unpublished studies with results through 'clinical trials.gov' and the American Society of Clinical Oncology (ASCO) website. We supplemented the searches by reviewing the bibliographies of key papers.

\section{Eligibility criteria}

All randomized controlled trials that compared the efficacy of the liposome encapsulated doxorubicin with the conventional anthracyclines on any cancer with or without other chemotherapy were considered eligible for the analysis. The randomized controlled trials on pegylated liposomal doxorubicin $\left(\right.$ Doxil $^{\circledR} / \mathrm{CAELYX}^{\mathrm{mm}}$ ), non-pegylated liposomal doxorubicin (Myocet), and liposomal Daunorubicin (DaunoXome) pooled for the meta-analysis, irrespective of tumor types and stages. The controlled arms must include one of the conventional anthracyclines, epirubicin, daunorubicin, doxorubicin, idarubicin and mitoxantrone.

\section{Exclusion criteria}

Non randomized trials were excluded. Randomized controlled trials with two different anthracyclines, but neither of them are a liposomal anthracycline were also excluded. Incomplete ongoing randomized trials with no published results were excluded as well.

\section{Data extraction}

The following information about each trial was recorded: first author, journal name, year of publication, number of patients assigned, median age of the patients in each study, diagnosis, drug combinations and dose of treatment and the cumulative dose of anthracyclines. The adverse effects of the liposomal and conventional anthracyclines were analyzed in two arms. The variables for the adverse effects include cardiac toxicity, hematology toxicity, hand-foot syndrome 
Table 1 Characteristics of eligible trials in the meta-analysis

\begin{tabular}{|c|c|c|c|c|c|c|c|c|c|c|}
\hline \multirow{2}{*}{$\begin{array}{l}\text { Trial } \\
\\
\text { Gill et al. } \\
{[22]}\end{array}$} & \multirow{2}{*}{$\begin{array}{l}\text { Year } \\
1996\end{array}$} & \multirow{2}{*}{$\begin{array}{l}\begin{array}{l}\text { Median } \\
\text { age(LD) }\end{array} \\
37\end{array}$} & \multirow{2}{*}{$\begin{array}{l}\begin{array}{l}\text { Median } \\
\text { age(D) }\end{array} \\
37\end{array}$} & \multirow{2}{*}{$\begin{array}{l}\text { Tumor type } \\
\text { AIDS-KS } \\
\end{array}$} & \multirow{2}{*}{$\begin{array}{l}\text { Total } \\
232\end{array}$} & \multicolumn{2}{|c|}{$\begin{array}{l}\text { Number } \\
\text { of patients } \\
\text { LD D }\end{array}$} & \multirow{2}{*}{$\begin{array}{l}\begin{array}{l}\text { Control } \\
\text { arm drug }\end{array} \\
\text { Doxorubicin }\end{array}$} & \multirow{2}{*}{$\begin{array}{l}\begin{array}{l}\text { Dose of } \\
\text { anthracyclines }\end{array} \\
\mathrm{L} \text { dauno- } 40 \mathrm{mg} / \mathrm{m} 2 \text { Doxo- } 10 \mathrm{mg} / \mathrm{m} 2\end{array}$} & \multirow{2}{*}{$\begin{array}{l}\text { Liposomal } \\
\text { anthracycline }\end{array}$} \\
\hline & & & & & & 116 & 111 & & & \\
\hline $\begin{array}{l}\text { Northfelt } \\
\text { et al. [23] }\end{array}$ & 1998 & 36 & 38 & AIDS-KS & 258 & 133 & 125 & Doxorubicin & PLD-20 mg/m2D-20 mg/m2 & PLD \\
\hline $\begin{array}{l}\text { Judson et al. } \\
\text { [24] }\end{array}$ & 2000 & 52 & 52 & $\begin{array}{l}\text { Metastatic } \\
\text { soft tissue } \\
\text { sarcoma }\end{array}$ & 94 & 50 & 44 & Doxorubicin & PLD-50 mg/m2D- 75 mg/m2 & PLD (CAELYX) \\
\hline $\begin{array}{l}\text { Harris et al. } \\
{[8]}\end{array}$ & 2001 & 58 & 58 & MBC & 224 & 108 & 116 & Doxorubicin & $\begin{array}{l}\text { LED- } 75 \text { mgDoxorubicin- } \\
75 \text { mg/m2 }\end{array}$ & Myocet \\
\hline $\begin{array}{l}\text { Batist et al. } \\
\text { [16] }\end{array}$ & 2001 & 55 & 54 & MBC & 297 & 142 & 155 & Doxorubicin & LED-60 mg/m2Doxo-60 mg/m2 & Myocet \\
\hline $\begin{array}{l}\text { O'Brien et al. } \\
\text { [14] }\end{array}$ & 2003 & 59 & 58 & MBC & 509 & 254 & 255 & Doxorubicin & PLD-50 mg/m2D- 60 mg/m2 & PLD \\
\hline $\begin{array}{l}\text { Dimopoulos } \\
\text { et al. } \\
{[25]}\end{array}$ & 2003 & 66 & 65 & $\mathrm{MM}$ & 259 & 132 & 127 & Doxorubicin & doxil-40 mgdoxo-9 mg/m2 & Doxil bolus \\
\hline Chan et al. [26] & 2004 & 54 & 54 & MBC & 160 & 80 & 80 & Epirubicin & LD-75 mg/m2D-75 mg/m2 & Myocet \\
\hline Rifkin et al. [27] & 2005 & 60 & 60 & MM & 192 & 97 & 95 & Doxorubicin & Doxil-40 mgDoxo-9 mg/m2 & Doxil \\
\hline
\end{tabular}

Abbreviations: AIDS-KS: Acquired immune deficiency syndrome- Kaposi Sarcoma; D: Doxorubicin; LD: Liposomal Doxorubicin; L Dauno: Liposomal Daunorubicin; MBC: Metastatic Breast Cancer; MM: Multiple Myeloma; PLD: Pegylated Liposomal Doxorubicin.

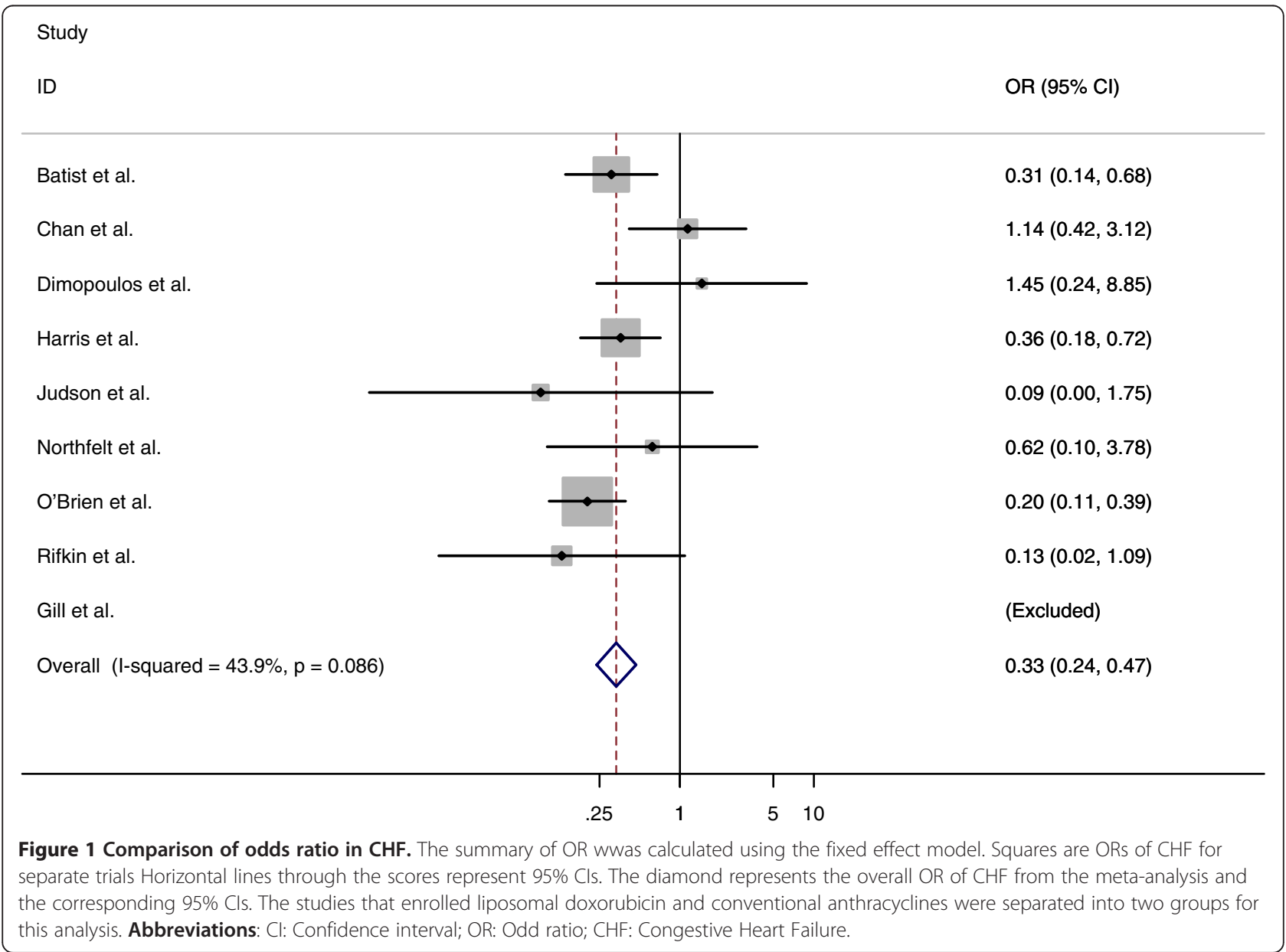


or palmar plantar erythrodysesthesia (PPE), febrile neutropenia, alopecia, nausea and vomiting.

Different criteria were used to define the grade of toxicity. The majority of the trials (6 out of 9) used the National Cancer Institute-Common Toxicity Criteria (NCI-CTC). The remaining two trials used the WHO criteria for toxicity and one trial used South West Oncology Group (SWOG) toxicity scoring system. The differences on the toxicity grading of the variables were essentially unremarkable among the criteria [21].

The primary end points were the adverse effects: cardiac toxicity with congestive cardiac failure and significant reduction in the left ventricular ejection fraction (LVEF) were entered in separate arms. The information about the cumulative dose and cardiac toxicity was extrapolated in a separate excel sheet. Four out of the nine studies provided the data about the cumulative doses at which cardiac toxicity was developed. Analysis of cardiotoxicity included comparison of the proportion of patients in each treatment group who developed cardiotoxicity (by protocol specified cardiac event) at any time during the study, as well as comparison of the mean percentage change in LVEF from baseline.
The hematology toxicities (anemia, leukopenia, neutropenia and thrombocytopenia) were extracted to four variables representing the grades of toxicity. The information of the different grades of hematology toxicity was not available in two of the trials. We analyzed the number of the incidence of toxicity of any grade giving specific importance to the grade toxicity.

There is difference in the grading of alopecia between the WHO and NCI- CTC criteria. Alopecia, either partial or complete, was analyzed as one variable.

The nausea and vomiting were included as one variable. Two studies did not include the information about nausea and vomiting. Four out of 9 studies did not have grading for toxicity. Toxicity of all grades was therefore considered as a single variable.

\section{Statistical analysis}

We performed the meta- analysis using the statistical software 'Stata' 10 version (statistics and Data created by Stata corp.). The existence of heterogeneity was tested using the Chi square statistics. The heterogeneity was quantified using the I-squared. For those variables with high heterogeneity $(\mathrm{p}<0.05$ for I-squared analysis), the

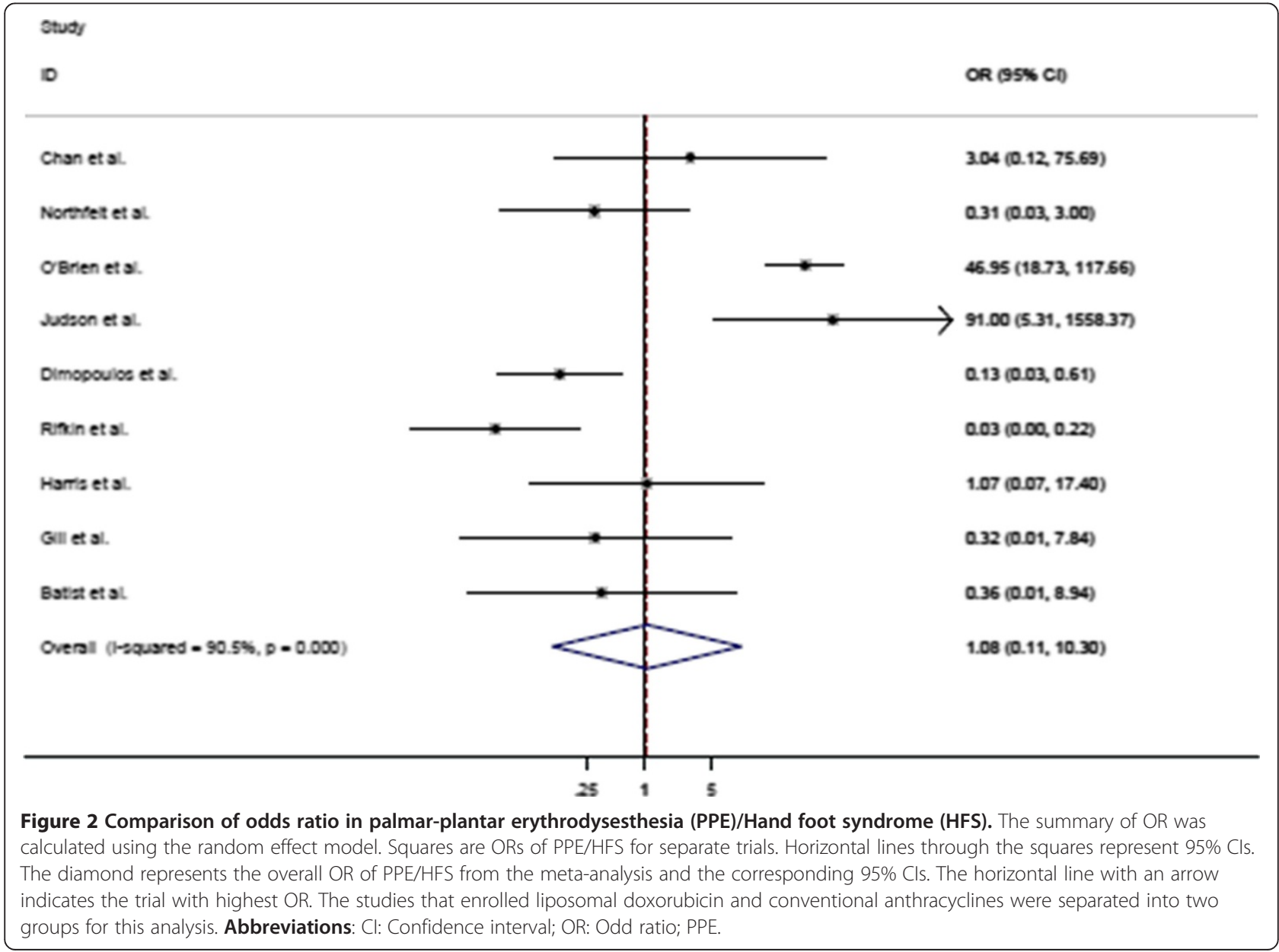


data were analyzed using the random effect model. Otherwise, fixed- effect model was used for the data analysis. We calculated the odds ratio (OR) with 95\% confidence intervals (CIs) from the data extracted from the original studies separately. The overall ORs were calculated from the pooled data. We eliminated studies if the data were not available for a particular variable.

\section{Results}

\section{Characteristics of the studies}

Nine randomized controlled trials that enrolled a total of 2220 patients were selected for the meta-analysis (Table 1). 1112 patients were treated with liposome encapsulated anthracyclines, including 666 who received PLD, 330 who received LD, and 116 who received liposomal daunorubicin. 1108 patients received the conventional anthracyclines, including 80 who received epirubicin, and 1028 who received doxorubicin. The trials included four metastatic breast cancer trials, two multiple myeloma trials, two AIDS-related soft tissue sarcoma trials and one metastatic soft tissue sarcoma trials. Five of the studies used Pegylated liposomal formulation Doxil ${ }^{\circledR} /$
CAELYX and doxorubicin, four trials used non- pegylated liposomal formulations (Myocet ${ }^{\mathrm{T} / \mathrm{T}} /$ Liposomal Daunorubicin) and conventional anthracyclines.

\section{Cardiotoxicity}

The cardiotoxicity (Figure 1) was higher with the doxorubicin group in five trails, whereas three other trials $[14,25,26]$ did not show significant difference in cardiac toxicity in both doxorubicin and liposomal doxorubicin group. One trial did not report data on cardiac toxicity and therefore was not included for analysis of the cardiotoxicity [22]. The median cumulative dose of the doxorubicin in both forms was reported in six of the eight trials analyzed. The median cumulative dose is higher with the liposomal formulation in three of the trials $[22,23,27]$, lower in one trial [14] and same in two trials [16,24].

Three studies $[14,16,26]$ compared the CHF or change in LVEF based on the cumulative dose of anthracyclines. In the study by Chan et al., the number of patients with decrease in LVEF under a cumulative dose of $<450 \mathrm{mg} /$ $\mathrm{m}^{2}$ were 5 and 8 for liposomal doxorubicin and epirubicin, respectively. The change in LV function and CHF above

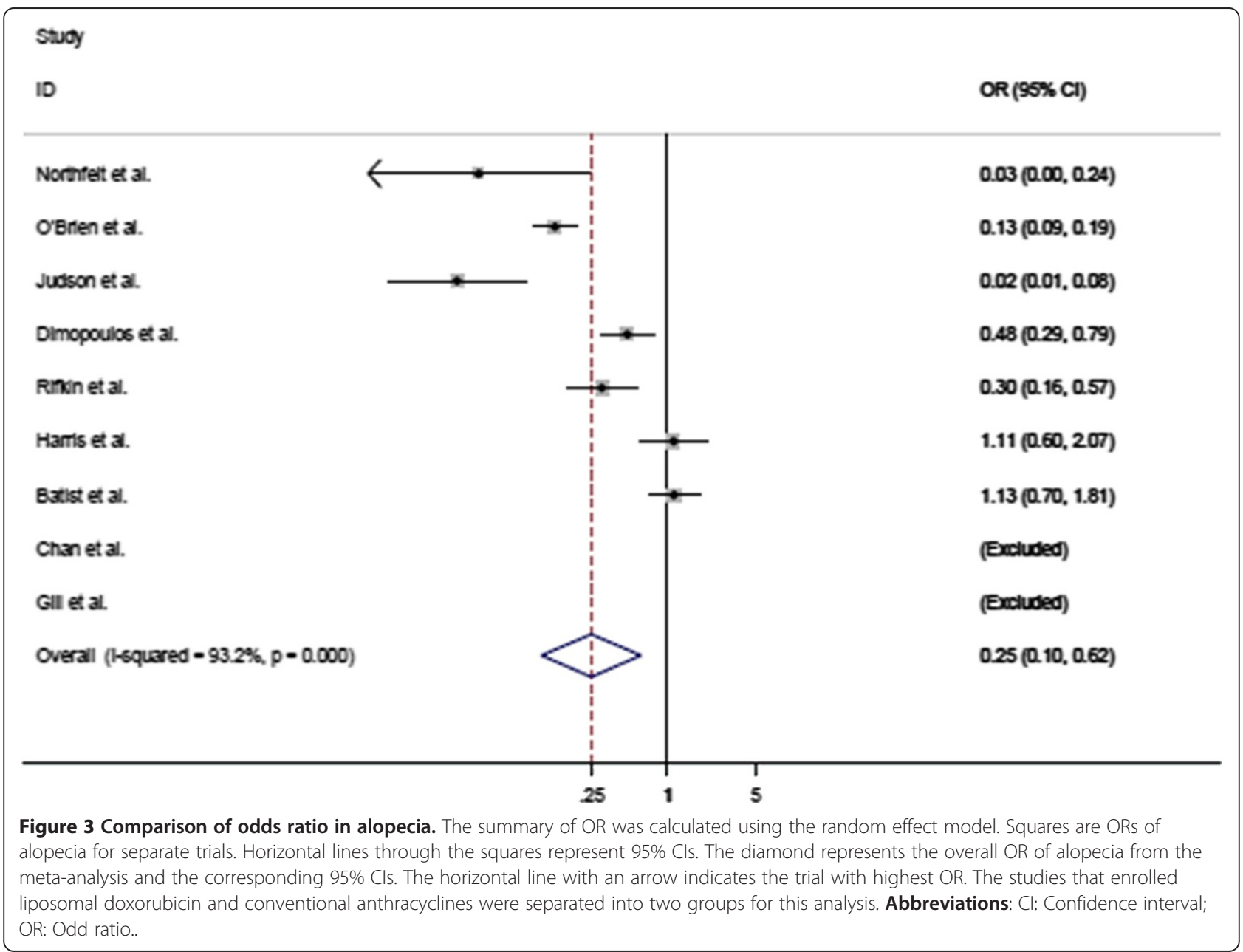


and below the cumulative dose of $450 \mathrm{mg} / \mathrm{m}^{2}$ was lower with liposomal doxorubicin in O'Brien [14] and Batist [16] studies. In the study by Batist et al., the estimated median cumulative life time dose for cardiac toxicity was $2220 \mathrm{mg} / \mathrm{m}^{2}$ for the liposomal group and $480 \mathrm{mg} / \mathrm{m}^{2}$ for the non liposomal group.

The odds ratio for the study conducted by Chan [26] and Dimopoulos [25] were 1.14 and 1.45, respectively, which is in favor of the non liposomal arm. The odds ratios of six trials were in favor of the liposomal arm. The pooled analyses were statistically significantly in favor of the liposomal arm compared with the conventional anthracyclines. The combined odds ratio for the pooled result is 0.335 (95\% CI $(0.238-0.471, \mathrm{p}=0.086)$.

\section{Palmar-plantar erythrodysesthesia (PPE)/hand-foot syndrome}

Five trials used pegylated liposomal doxorubicin. Four trials used non pegylated liposomal anthracyclines (Figure 2). The odds ratios for PPE in five trials were in favor of the liposomal arm, the other four trials favored of the nonliposomal anthracyclines. The combined odds ratio of the trials were 1.08 (95\% CI $0.11-10.30, \mathrm{p}=0.947)$. Therefore, the overall result of the nine trials did not show statistically significant advantage of conventional anthracyclines over liposomal preparations in PPE events.

\section{Alopecia}

The incidence of alopecia (Figure 3) showed consistent results in 5 studies, whereas three studies showed no significant difference in the incidence of alopecia. The trials $[14,23-25,27]$ showed significantly lower incidence of alopecia. All these trials compared PLD with doxorubicin. The three trials $[8,16,26]$ that compared myocet with conventional anthracyclines failed to show a significant difference in the alopecia incidence. The overall odds ratio from the pooled analysis was 0.25 (95\% CI $0.10-0.62, \mathrm{p}=0.003)$.

\section{Neutropenia}

The incidence was counted for all grades of neutropenia. The odds ratios of eight of the nine trials are in favor of the liposomal doxorubicin (Figure 4). One study showed similar toxicity on both arms. The pooled result is in



Figure 4 Comparison of odds ratio in neutropenia. The summary of OR was calculated using the random effect model. Squares are ORs of neutropenia for separate trials. Horizontal lines through the squares represent $95 \% \mathrm{Cls}$. The diamond represents the overall OR of neutropenia from the meta-analysis and the corresponding $95 \% \mathrm{Cls}$. The studies that enrolled liposomal doxorubicin and conventional anthracyclines were separated into two groups for this analysis. Abbreviations: Cl: Confidence interval; OR: Odd ratio. 
favor of the liposomal doxorubicin with an Odds ratio of $0.62(95 \% \mathrm{CI}$ is $0.45-0.85, \mathrm{p}=0.003)$.

\section{Febrile neutropenia}

The odds ratios of all 9 studies were analyzed. The odds ratios of Chan, Dimpoulos, Gill, Harris and Northfelt studies were in favor of the non liposomal anthracyclines. The odds ratios of Batist, Judson, Northfelt and Rifkin studies were in favor of the liposomal arm. The overall OR for the pooled analysis of the nine trials was 0.89 (95\% CI $0.55-1.44, \mathrm{p}=0.639$ ), making both arms essentially similar adverse events of febrile neutropenia (Figure 5).

The other hematological toxicities anemia and thrombocytopenia were also in favor of the liposomal arm. The odd ratios of anemia and thrombocytopenia were $0.89(\mathrm{CI} ; 0.71-1.12)$ and $0.87(\mathrm{CI} ; 0.61-1.25)$ respectively. The incidence of nausea and vomiting was less with the liposomal arm with an odd ratio of 0.79 (CI; 0.66-0.96).

\section{Discussion}

This meta-analysis included nine randomized controlled trials comparing liposomal and conventional anthracyclines.

Previous studies [28] have shown that the incidence of anthracycline induced $\mathrm{CHF}$ is directly proportional to the cumulative dose of anthracyclines. Northfelt, O'Brien and Batist plotted the relationship of cumulative dose of liposomal anthracyclines and conventional anthracyclines $[14,16,23]$. In this meta-analysis, the odds ratio reveals the incidence of cardiotoxicity to be significantly lower with the liposomal anthracyclines. The heterogeneity of the studies was low and the $\mathrm{I}^{2}$ showed moderate heterogeneity for the cardiac toxicity. This study therefore confirms that the liposomal anthracyclines offer an alternative to conventional anthracyclines for patients with previous history of cardiac disease, elderly patients, and prior use of anthracyclines who are at high risk to develop cardiac toxicity. The safety profile with high cumulative dose range of liposomal anthracyclines favors the use of liposomal anthracyclines on patients who

\section{Study}

$\begin{array}{ll}\text { ID } & O R(95 \% \mathrm{Cl})\end{array}$

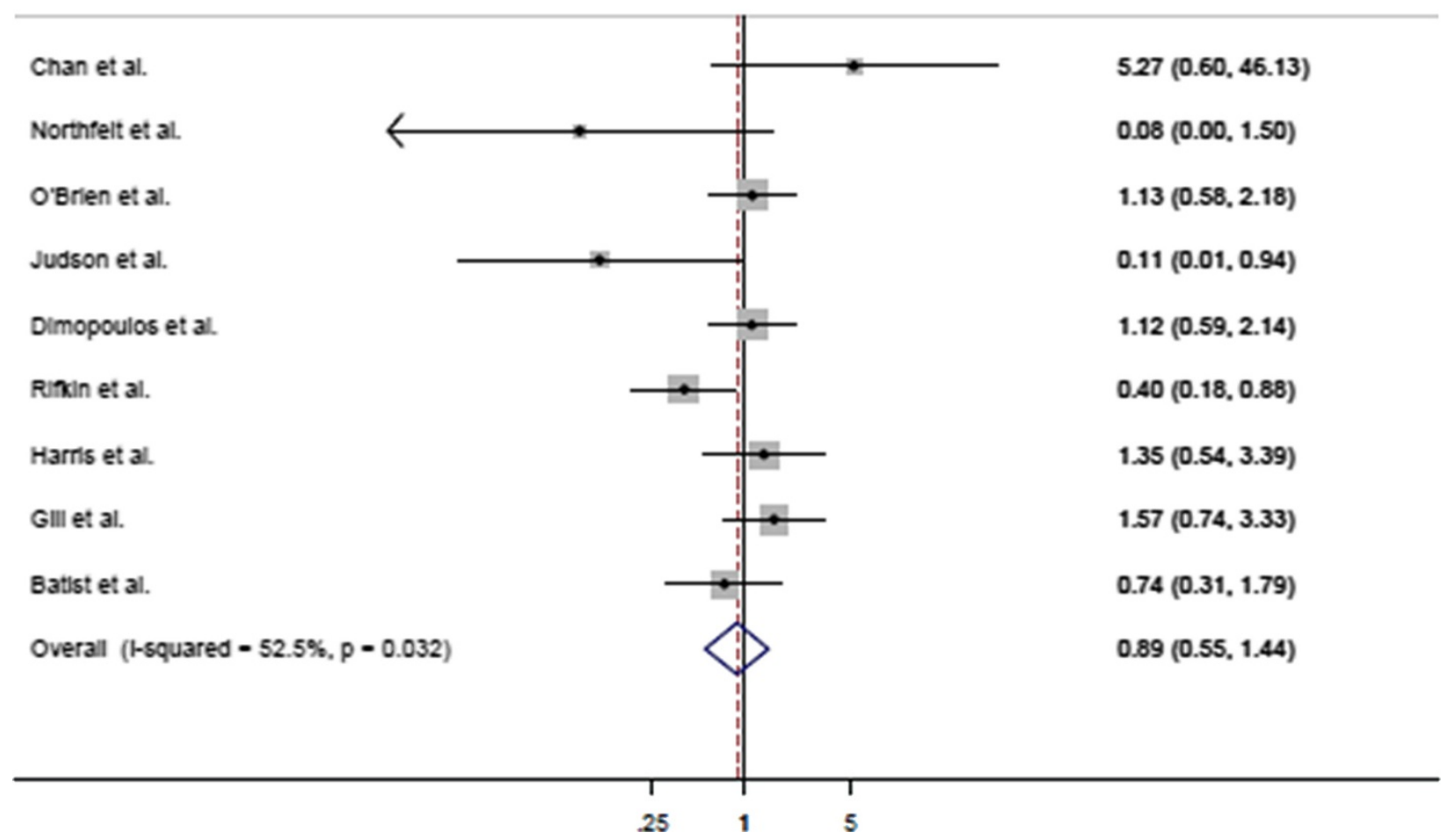

Figure $\mathbf{5}$ Comparison of odds ratio in febrile neutropenia. The summary of OR was calculated using the random effect model. Squares are ORs of febrile neutropenia for separate trials. Horizontal lines through the squares represent $95 \% \mathrm{Cls}$. The diamond represents the overall OR of Febrile Neutropenia from the meta-analysis and the corresponding 95\% Cls. The horizontal line with an arrow indicates the trial with highest OR. The studies that enrolled liposomal doxorubicin and conventional anthracyclines were separated into two groups for this analysis. Abbreviations: Cl: Confidence interval; OR: Odd ratio. 
were previously treated with anthracyclines. The cardiac safety profile of the liposomal formulations of anthracyclines suggests the potential to use it in combination with trastuzumab in HER2 positive breast cancer.

The incidence of hematological toxicity of all grades was lower with liposomal anthracyclines. The incidences of neutropenia were significantly lower with liposomal anthracyclines, although there were no significant differences in febrile neutropenia. The lower incidence of myelosuppression makes the liposomal anthracyclines particularly more desirable for elderly patients.

PPE is a dose limiting toxicity of pegylated liposomal doxorubicin, doxil, which is the only liposomal doxorubicin approved in USA, even though the meta-analysis did not show significant differences in PPE.

The main limitations of the study are the heterogeneity of study groups. Though there was no difference within the study in each group, there were variations among different studies based on various factors. The primary cancer treated was metastatic breast cancer in four trials, multiple myeloma in two trials, AIDS related Kaposi sarcoma in two trials and metastatic soft tissue sarcoma in one trial. Due to the different tumor types, the study drugs varied in the dose, frequency and number of treatment. However, the intergroup variations have a limited effect on our meta-analysis due to the fact that each trial is randomized and well controlled. There are no variations among the two groups within the studies. The existence of heterogeneity among the study group was evaluated using the chi-squared analysis. The extent of heterogeneity was assessed using the I-squared analysis. Moderate to high heterogeneity was noted among the study groups. To minimize the bias, we used random effects models for the studies with high heterogeneity, as recommended and performed by many statisticians and meta-analysis publications [29-31].

\section{Conclusions}

Liposomal doxorubicin and pegylated liposomal doxorubicin demonstrated favorable toxicity profiles with better cardiac safety and less myelosuppression, alopecia, nausea and vomiting compared with the conventional antracyclines. The better therapeutic index of liposomal anthracyclines without compromising the efficacy makes it a favorable choice over conventional anthracyclines in elderly patients, patients with risk factors for cardiac disease and patients with prior use of anthracylines.

\section{Competing interests}

The authors have no relevant conflict of interests.

\section{Acknowledgements}

This study was supported in part by NYMC Blood Disease Fund (DL).

\section{Author details}

'Division of Hematology and Oncology, New York Medical College and Westchester Medical Center, Valhalla, NY 10595, USA. Bone Marrow Transplantation Center, the First Affiliated Hospital, Zhejiang University School of Medicine, Hangzhou, China.

\section{Authors' contributions}

SMR and DL participated in concept design, data collection and analysis, drafting and critically revising the manuscript. MR participated in data analysis and figure preparation. BL, GL and GW participated in reference preparation and formatting. All authors read and approved the final manuscript.

Received: 14 February 2012 Accepted: 15 March 2012

Published: 23 April 2012

\section{References}

1. Takahashi S: Current findings for recurring mutations in acute myeloid leukemia. J Hematol Oncol 2011, 4:36.

2. Takahashi S: Downstream molecular pathways of FLT3 in the pathogenesis of acute myeloid leukemia: biology and therapeutic implications. J Hematol Oncol 2011, 4:13.

3. Zhu X, Ma Y, Liu D: Novel agents and regimens for acute myeloid leukemia: 2009 ASH annual meeting highlights. J Hematol Oncol 2010, 3:17.

4. Rivera E: Liposomal anthracyclines in metastatic breast cancer: clinical update. Oncologist 2003, 8(Suppl 2):3-9.

5. Barrett-Lee PJ, Dixon JM, Farrell C, Jones A, Leonard R, Murray N, Palmieri C, Plummer CJ, Stanley A, Verrill MW: Expert opinion on the use of anthracyclines in patients with advanced breast cancer at cardiac risk. Annals of oncology: official journal of the European Society for Medical Oncology/ESMO 2009, 20(5):816-827.

6. Zhang SH, Wang WQ, Wang JL: Protective effect of tetrahydroxystilbene glucoside on cardiotoxicity induced by doxorubicin in vitro and in vivo. Acta Pharmacol Sin 2009, 30(11):1479-1487.

7. O'Shaughnessy J: Liposomal anthracyclines for breast cancer: overview. Oncologist 2003, 8(Suppl 2):1-2.

8. Harris L, Batist G, Belt R, Rovira D, Navari R, Azarnia N, Welles L, Winer E, Group TDS: Liposome-encapsulated doxorubicin compared with conventional doxorubicin in a randomized multicenter trial as first-line therapy of metastatic breast carcinoma. Cancer 2002, 94(1):25-36.

9. Lopez-Berestein G, Fidler IJ, CIBA-GEIGY Corporation: Liposomes in the therapy of infectious diseases and cancer: proceedings of a Ciba-GeigySquibb-UCLA colloquium, held at Lake Tahoe, California, February 16-20, 1988. New York: Liss E.R. Squibb \& Sons., University of California Los Angeles; 1989

10. Al-Batran SE, Meerpohl HG, von Minckwitz G, Atmaca A, Kleeberg U, Harbeck N, Lerbs W, Hecker D, Sehouli J, Knuth A, et al: Reduced incidence of severe palmar-plantar erythrodysesthesia and mucositis in a prospective multicenter phase II trial with pegylated liposomal doxorubicin at $40 \mathrm{mg} / \mathrm{m} 2$ every 4 weeks in previously treated patients with metastatic breast cancer. Oncology 2006, 70(2):141-146.

11. Safra T: Cardiac safety of liposomal anthracyclines. Oncologist 2003, 8(Suppl 2):17-24.

12. Simunek T, Sterba M, Popelova O, Adamcova M, Hrdina R, Gersl V: Anthracycline-induced cardiotoxicity: overview of studies examining the roles of oxidative stress and free cellular iron. Pharmacological reports: PR 2009, 61(1):154-171.

13. Allen TM, Mumbengegwi DR, Charrois GJ: Anti-CD19-targeted liposomal doxorubicin improves the therapeutic efficacy in murine B-cell lymphoma and ameliorates the toxicity of liposomes with varying drug release rates. Clinical cancer research: an official journal of the American Association for Cancer Research 2005, 11(9):3567-3573.

14. O'Brien ME, Wigler N, Inbar M, Rosso R, Grischke E, Santoro A, Catane R, Kieback DG, Tomczak P, Ackland SP, et al: Reduced cardiotoxicity and comparable efficacy in a phase III trial of pegylated liposomal doxorubicin $\mathrm{HCl}$ (CAELYX/Doxil) versus conventional doxorubicin for first-line treatment of metastatic breast cancer. Annals of oncology: official journal of the European Society for Medical Oncology/ESMO 2004, 15(3):440-449 
15. Balazsovits JA, Mayer LD, Bally MB, Cullis PR, McDonell M, Ginsberg RS, Falk RE: Analysis of the effect of liposome encapsulation on the vesicant properties, acute and cardiac toxicities, and antitumor efficacy of doxorubicin. Cancer Chemother Pharmacol 1989, 23(2):81-86.

16. Batist G, Ramakrishnan G, Rao CS, Chandrasekharan A, Gutheil J, Guthrie T, Shah P, Khojasteh A, Nair MK, Hoelzer K, et al: Reduced cardiotoxicity and preserved antitumor efficacy of liposome-encapsulated doxorubicin and cyclophosphamide compared with conventional doxorubicin and cyclophosphamide in a randomized, multicenter trial of metastatic breast cancer. Journal of clinical oncology: official journal of the American Society of Clinical Oncology 2001, 19(5):1444-1454.

17. Kanter PM, Bullard GA, Ginsberg RA, Pilkiewicz FG, Mayer LD, Cullis PR Pavelic ZP: Comparison of the cardiotoxic effects of liposomal doxorubicin (TLC D-99) versus free doxorubicin in beagle dogs. In Vivo 1993, 7(1):17-26.

18. Kanter PM, Bullard GA, Pilkiewicz FG, Mayer LD, Cullis PR, Pavelic ZP: Preclinical toxicology study of liposome encapsulated doxorubicin (TLC D-99): comparison with doxorubicin and empty liposomes in mice and dogs. In Vivo 1993, 7(1):85-95.

19. Mayer LD, Bally MB, Cullis PR, Wilson SL, Emerman JT: Comparison of free and liposome encapsulated doxorubicin tumor drug uptake and antitumor efficacy in the SC115 murine mammary tumor. Cancer Lett 1990, 53(2-3):183-190

20. Mayer LD, Tai LC, Bally MB, Mitilenes GN, Ginsberg RS, Cullis PR: Characterization of liposomal systems containing doxorubicin entrapped in response to pH gradients. Biochim Biophys Acta 1990, 1025(2):143-151.

21. Franklin HR, Simonetti GP, Dubbelman AC, ten Bokkel Huinink WW, Taal BG, Wigbout G, Mandjes IA, Dalesio OB, Aaronson NK: Toxicity grading systems. A comparison between the WHO scoring system and the Common Toxicity Criteria when used for nausea and vomiting. Annals of oncology: official journal of the European Society for Medical Oncology/ESMO 1994, 5(2):113-117

22. Gill PS, Wernz J, Scadden DT, Cohen P, Mukwaya GM, von Roenn JH, Jacobs $M$, Kempin S, Silverberg I, Gonzales G, et al: Randomized phase III trial of liposomal daunorubicin versus doxorubicin, bleomycin, and vincristine in AIDS-related Kaposi's sarcoma. Journal of clinical oncology: official journal of the American Society of Clinical Oncology 1996, 14(8):2353-2364.

23. Northfelt DW, Dezube BJ, Thommes JA, Miller BJ, Fischl MA, Friedman-Kien A, Kaplan LD, Du Mond C, Mamelok RD, Henry DH: Pegylated-liposomal doxorubicin versus doxorubicin, bleomycin, and vincristine in the treatment of AIDS-related Kaposi's sarcoma: results of a randomized phase III clinical trial. Journal of clinical oncology: official journal of the American Society of Clinical Oncology 1998, 16(7):2445-2451.

24. Judson I, Radford JA, Harris M, Blay JY, van Hoesel Q, le Cesne A, van Oosterom AT, Clemons MJ, Kamby C, Hermans C, et al: Randomised phase II trial of pegylated liposomal doxorubicin (DOXIL/CAELYX) versus doxorubicin in the treatment of advanced or metastatic soft tissue sarcoma: a study by the EORTC Soft Tissue and Bone Sarcoma Group. Eur J Cancer 2001, 37(7):870-877.

25. Dimopoulos MA, Pouli A, Zervas K, Grigoraki V, Symeonidis A, Repoussis P Mitsouli C, Papanastasiou C, Margaritis D, Tokmaktsis A, et al: Prospective randomized comparison of vincristine, doxorubicin and dexamethasone (VAD) administered as intravenous bolus injection and VAD with liposomal doxorubicin as first-line treatment in multiple myeloma. Annals of oncology: official journal of the European Society for Medical Oncology/ESMO 2003, 14(7):1039-1044.

26. Chan S, Davidson N, Juozaityte E, Erdkamp F, Pluzanska A, Azarnia N, Lee LW: Phase III trial of liposomal doxorubicin and cyclophosphamide compared with epirubicin and cyclophosphamide as first-line therapy for metastatic breast cancer. Annals of oncology: official journal of the European Society for Medical Oncology/ESMO 2004, 15(10):1527-1534.

27. Rifkin RM, Gregory SA, Mohrbacher A, Hussein MA: Pegylated liposomal doxorubicin, vincristine, and dexamethasone provide significant reduction in toxicity compared with doxorubicin, vincristine, and dexamethasone in patients with newly diagnosed multiple myeloma: a Phase III multicenter randomized trial. Cancer 2006, 106(4):848-858.

28. Von Hoff DD, Layard MW, Basa P, Davis HL Jr, Von Hoff AL, Rozencweig M, Muggia FM: Risk factors for doxorubicin-induced congestive heart failure. Ann Intern Med 1979, 91(5):710-717.
29. Huedo-Medina TB, Sanchez-Meca J, Marin-Martinez F, Botella J: Assessing heterogeneity in meta-analysis: Q statistic or 12 index?. Psychol Methods 2006, 11(2):193-206.

30. Hu J, Zhao G, Wang HX, Tang L, Xu YC, Ma Y, Zhang FC: A meta-analysis of gemcitabine containing chemotherapy for locally advanced and metastatic pancreatic adenocarcinoma. J Hematol Oncol 2011, 4:11.

31. Wei G, Ni W, Chiao JW, Cai Z, Huang H, Liu D: A meta-analysis of CAG (cytarabine, aclarubicin, G-CSF) regimen for the treatment of 1029 patients with acute myeloid leukemia and myelodysplastic syndrome. J Hematol Oncol 2011, 4:46.

doi:10.1186/2162-3619-1-10

Cite this article as: Rafiyath et al.: Comparison of safety and toxicity of liposomal doxorubicin vs. conventional anthracyclines: a meta-analysis. Experimental Hematology \& Oncology 2012 1:10.

\section{Submit your next manuscript to BioMed Central and take full advantage of:}

- Convenient online submission

- Thorough peer review

- No space constraints or color figure charges

- Immediate publication on acceptance

- Inclusion in PubMed, CAS, Scopus and Google Scholar

- Research which is freely available for redistribution

Submit your manuscript at www.biomedcentral.com/submit
C BioMed Central 